\title{
Assessing the Pressure and Thermal Discomfort Thresholds for Designing of Therapeutic Gloves: A Pilot Study
}

Siti Hana Nasir ${ }^{1,2}$, Olga Troynikov ${ }^{3}$, Dawn Wong Lit Wan ${ }^{4}$, Zhen Zheng ${ }^{4, *}$

1. Innovative Manufacturing Technology Research Group (IMT), Advanced Technology Centre (ATC), Department of Mechanical Engineering Technology, Faculty of Engineering Technology, Universiti Tun Hussein Onn Malaysia, Malaysia; E-Mail: sitihana@uthm.edu.my

2. School of Fashion and Textiles, RMIT University, Australia;

3. School of Engineering, RMIT University, Australia; E-Mail: olga.troynikov@rmit.edu.au

4. School of Health and Biomedical Sciences, RMIT University, PO Box 71, Bundoora Victoria, 3083, Australia; E-Mails: dawn.wonglitwan@rmit.edu.au, zhen.zheng@rmit.edu.au

* Correspondence: Zhen Zheng; E-Mail: zhen.zheng@rmit.edu.au

Academic Editor: Gerhard Litscher

Special Issue: Complementary Medicine and Pain Management

OBM Integrative and Complementary Medicine 2019, volume 4, issue 3

doi:10.21926/obm.icm.1903053
Received: February 25, 2019

Accepted: August 21, 2019

Published: September 02, 2019

\begin{abstract}
Background: Pressure and thermal therapy gloves are the two types of therapeutic gloves that are commonly used to relieve symptoms and improve hand function in patients with hand arthritis. However, no published clinical study exists indicating ideal pressure and thermal stimuli for the gloves. Understanding user thresholds for the pressure and thermal stimuli is crucial to improve therapeutic outcomes, wearer's comfort, and adherence to the therapy. There were two main aims of this pilot study, firstly to examine the pressure and thermal discomfort thresholds in different regions of the hand in individuals with hand osteoarthritis (OA) or rheumatoid arthritis (RA) and secondly to determine whether the Cold-Heat pattern questionnaire could be used as a tool to categorize patients into groups to decide over the right treatment option for a patient.
\end{abstract}

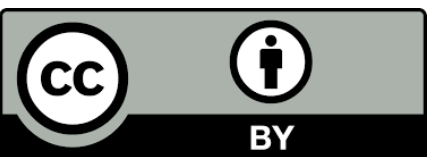

(C) 2019 by the author. This is an open access article distributed under the conditions of the Creative Commons by Attribution License, which permits unrestricted use, distribution, and reproduction in any medium or format, provided the original work is correctly cited. 
Design: Thirteen women with hand OA or RA participated in this exploratory study. The pressure and thermal discomfort thresholds were assessed over the first distal interphalangeal joint, second distal interphalangeal joint, third proximal interphalangeal joint, third metacarpophalangeal joint, and first carpometacarpal joint.

Results: Significant variations were observed among the participants in their pressure, cold, and heat discomfort thresholds. Some of the participants also recorded significantly different levels of sensitivity toward pressure, cold, and heat at different locations of the hand. Moderate correlations were found between the duration of arthritis and pressure discomfort thresholds, as well as between the duration of arthritis and cold discomfort thresholds; those with a longer duration of arthritis were significantly more sensitive toward pressure and cold. Based on Cold-Heat pattern questionnaire, eight participants were classified as individuals who are sensitive to cold (cold pattern group) and five participants were classified as individuals who are sensitive to heat (heat pattern group). There was no statistically significant difference in the means of pressure, cold and heat discomfort thresholds between the cold pattern group and the heat pattern group.

Conclusion: An ergonomic approach based on the variations in the distribution of human factors such as pressure and thermal sensitivity is recommended to be used in the design of therapeutic gloves. The role of the Cold-Heat pattern questionnaire in assisting the design of therapeutic gloves for particular groups of wearers requires further investigation.

\section{Keywords}

Therapeutic gloves; arthritis; pressure; thermal; discomfort thresholds

\section{Introduction}

Arthritis refers to a joint disorder that involves inflammation of one or more joints [1-3]. Pain and impaired hand function are the clinical representations of hand arthritis. A therapeutic glove is one of the non-pharmacological approaches available for patients with hand arthritis; especially for those in the early stage of the disease $[4,5]$. Different varieties of commercial therapeutic gloves with different designs, constructions, and materials, aiming to provide different functions such as reduction of hand symptoms (pain, stiffness, and swelling) and improvement of hand function, are available on the market [4].

The commonly used therapeutic glove designs are of two types. The first type of glove is designed to apply pressure on the underlying hand tissue and skin (pressure therapy). Different levels of pressure induced by the gloves have been reported in the literature [6, 7]; however, no clinical evidence exists indicating the ideal pressure for therapeutic gloves for people with hand arthritis [4]. Prolonged exposures to a high level of interface pressure can cause discomfort to wearers and may potentially be harmful, causing bruising, blistering, and development of ulcers [8-10]. Discomfort as a result of overpressure can also influence compliance and the overall goal of the treatment. Johansson, Kjellberg (11) studied the pressure discomfort thresholds in 24 healthy white-collar workers and found that the discomfort thresholds for finger and palm were $188 \mathrm{kPa}$ and $200 \mathrm{kPa}$, respectively, and the discomfort thresholds were significantly different among the 
male and female participants. This study shows that physiology varies significantly between the locations of hand and also among individuals, which can affect perceptions of comfort. Chiarotto, Fernandez-de-Las-Penas (12) found that patients with thumb OA demonstrated widespread hypersensitivity to mechanical pressure stimuli when compared to healthy subjects. The decrease in pressure pain thresholds was associated with the intensity and duration of pain, supporting the role of central sensitization [13-15]. Central sensitization is defined as a mechanism in which the body exhibits an increased response to stimulation due to alteration within the central nervous system [16]. A deeper understanding of pressure discomfort thresholds in patients with hand arthritis in different areas of hand could be a useful measure to facilitate achievement of optimal pressure between the glove and hand.

The second type of glove is made to provide warmth to the wearer (heat therapy). Although this type of glove is widely used, only a few studies have been focused on this. It has been reported that this glove could be too warm and negatively influence wearers' adherence to the therapy $[4,5,17]$. To the best our knowledge, no published study has yet examined the optimum skin temperature required for the thermal modality of the glove to be effective and comfortable for the wearer. As arthritis sufferers can spend considerable time wearing therapeutic gloves, it is important to maintain their positive comfort sensations during wear. Psychophysical studies have shown that sensitivities to thermal stimulation are not uniformly distributed across the body regions and also differ between individuals [18-20]. Li, Petrini (18) reported a high-resolution topographical mapping of warm and cold sensitivities of the hand in healthy participants. They found that thermal sensitivity distribution in the hand is not uniformly distributed; the palm is more sensitive than the fingers to both warm and cold stimuli. They also found females participants to be more sensitive than male participants to both warm and cold stimuli. Wakolbinger, Roche (19) found that the dorsal side of the hand was significantly more sensitive than the palmar side of the hand to both cold and warm stimuli and differed in both cold and heat pain thresholds. They concluded that the dorsal side of the hand is more sensitive to temperature changes than corresponding palmar regions.

The differences in pressure and thermal discomfort thresholds between individuals and in different areas of the hand emphasize that the design of the gloves must take into consideration these differences together with severity of arthritis. These factors together with the esthetic concerns such as color selection, fabric handle, and overall style contribute to the wearer's sense of well-being and confidence. To date, only a few researchers working on ergonomic design of working gloves [21, 22] have considered the pressure tolerance of hand in the design process. Muralidhar, Bishu (22) considered the force distribution patterns on the palmar side of the hand from various studies to develop an ergonomic glove where protective material is introduced at varying levels over different parts of the hand that needed protection. In order to achieve optimal comfort and functionality of therapeutic gloves, regional variations in term of pressure and thermal sensitivity of individuals with hand arthritis need to be included in the design of therapeutic gloves.

As such, the present pilot study aimed at examining the pressure and thermal discomfort thresholds in different regions of the hand in individuals with hand OA or RA. The distribution of pressure and thermal sensitivity can be used as the inputs to design therapeutic gloves if the relationship between them is well understood. Secondly, we aimed to determine whether the Cold-Heat pattern questionnaire [23] could be used as a tool to classify patients into groups so 
that the right treatment option can be targeted for a wearer. In Chinese medicine, a Cold-Heat pattern questionnaire is used to divide patients into two groups: cold pattern group and heat pattern group. Based on this classification, the patients in each group are treated differently, where individuals with a cold pattern are prescribed with heat therapy whereas their heat counterparts - with cold therapy [23-25]. It was expected that individuals belonging to the cold or heat pattern group will elicit different responses to different therapeutic gloves [25]. Therefore, it is reasonable to hypothesize that Cold-Heat pattern questionnaire could help design gloves for a particular group of people that will respond optimally to different therapy, i.e., thermal glove or pressure glove or combination of both.

\section{Methods}

The experimental procedures were approved by the RMIT University Human Research Ethics Committee (project number 19653). The participants were informed about the purpose of the study and assured for the confidentiality of their data. The participants provided written informed consent and received no remuneration for participating in this study.

\subsection{Participants}

Thirteen women were recruited through advertisement on websites, posters, and flyers distributed in the local area. The subjects chosen in this study were only female, as arthritis is significantly more dominant among women and its occurrence increases with age. The statistics were found to be in agreement with our study and previous studies [26-28]. Since this is a pilot study, we expect that future studies could investigate if there is any gender difference in the outcomes.

The inclusion criteria for the participants were (1) age 40-70 years; (2) diagnosed with hand OA or RA by a general practitioner or rheumatologist or a registered healthcare practitioner; and (3) ability to have an adequate conversation in English.

The exclusion criteria were (1) history of the upper extremity or neck pain, fractures, or any neurologic disorder; (2) pregnant or planning to be pregnant; (3) injuries in the area to be tested.

\subsection{Experimental Procedure}

Each participant underwent pressure stimulation followed by thermal (cold and heat) stimulation, with a 10-min break in between. During the break, the participants were asked to answer the Cold-Heat pattern questionnaire. Discomfort thresholds to pressure and thermal stimulation were measured. Discomfort threshold is the level of stimulus at which the innocuous sensation changes to a discomfort [29].

Five test sites on the dorsal side of the hand (Figure 1) were selected for the study: P1-first distal interphalangeal (DIP) joint, P2-second DIP joint, P3-third proximal interphalangeal (PIP) joint, P4-third metacarpophalangeal (MCP) joint, and P5-first carpometacarpal (CMC) joint. The sites were chosen based on two factors: a high distribution of skin deformation as reported in our previous study [26], and the common sites for the occurrence of hand OA and RA [30-34]. The hand with greater arthritic pain was chosen for the testing. 
All the experiments were carried out in an environmentally-controlled chamber maintained under standard testing conditions $\left(20 \pm 2{ }^{\circ} \mathrm{C}, 65 \pm 3 \%\right.$ relative humidity). All participants were in the seated position with their arms resting on a table. The participants were assured that the pressure, cold or heat stimulation would not cause any physical damage to their hand and were allowed to withdraw from the experiments at any time. The pressure and thermal thresholds were assessed by the same assessor and the sequence for assessing the five individual locations was randomized.

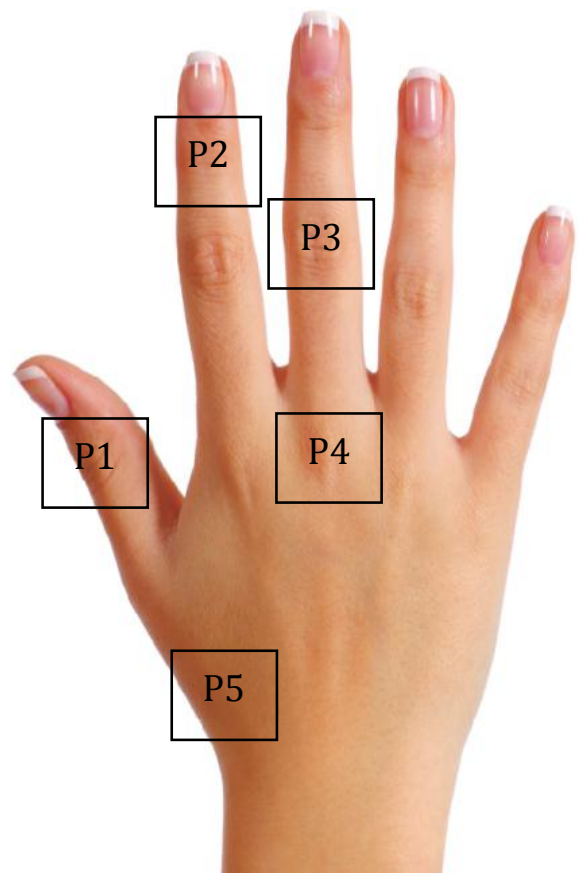

Figure 1 Measuring sites on the participant's hand.

The Cold-Heat pattern questionnaire developed and validated by Ryu, Lee (23) was used to classify the participants into cold pattern or heat pattern groups. This questionnaire consists of two sections: Cold questionnaire and Heat questionnaire. The Cold-Heat pattern questionnaire score was then calculated by adding up all the relevant item scores and subtracting the Cold questionnaire score from the Heat questionnaire score [23]. The participants with a negative score were classified into cold pattern group (those who are sensitive to cold), whereas those with a positive score were classified into heat pattern group (those are sensitive to heat).

\subsubsection{Self-Report Measures}

The participants were instructed to record the intensity and mark the areas where arthritic pain was experienced in the past $24 \mathrm{~h}$ prior to the experiment on an anatomic map (Figure 2). They were taught to record the pain on a numerical rating scale of 0 to 10 , where 0 corresponded to 'no pain' and 10 corresponded to 'maximal pain. Pain could occur at any time during the past 24 $h$, such as during rest, movement or during the night. 


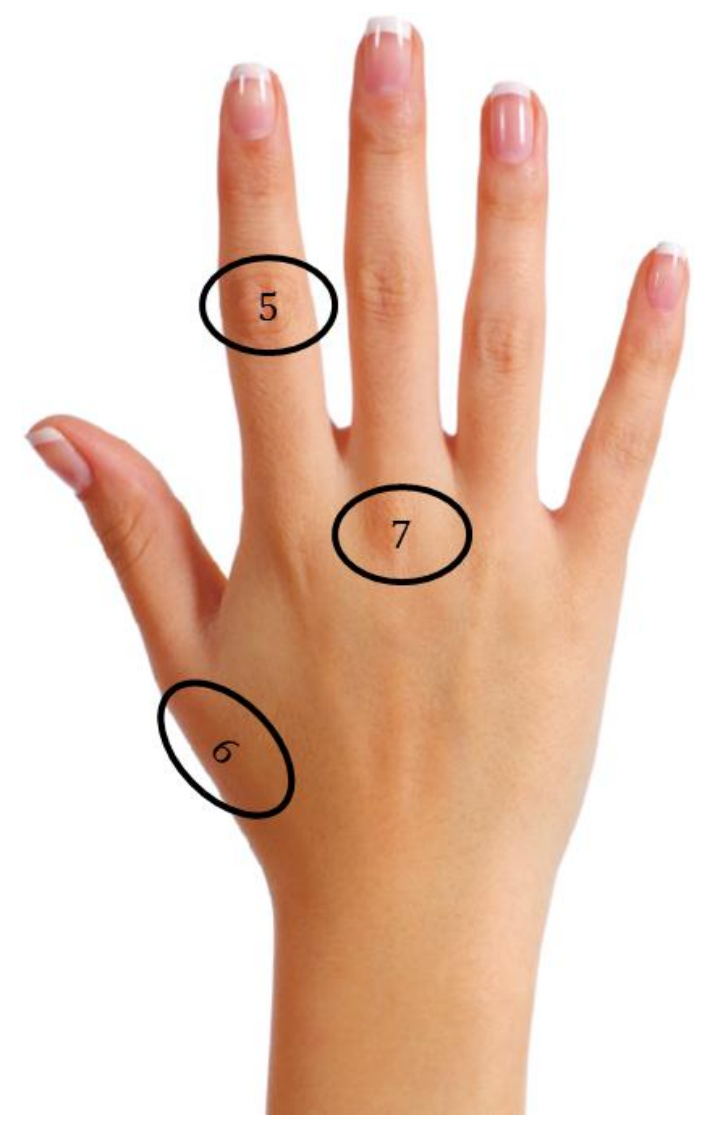

Figure 2 Example of mapping the locations and intensities of arthritic pain.

\subsubsection{Assessment of Pressure and Thermal Discomfort Thresholds}

A computerized algometer, with a probe surface of $1 \mathrm{~cm}^{2}$ (Algomed, Medoc, Ramat Yishai, Israel) was applied perpendicularly at the sites to measure the pressure discomfort thresholds. The pressure was applied at a rate of $30 \mathrm{kPa} / \mathrm{sec}$. The participants were instructed to press the cut-off switch when the sensation changed from pressure to a discomfort. The mean of three pressure discomfort thresholds at each site was recorded. Twenty seconds interval was allowed between each site.

A thermode with a size of $16 \times 16 \mathrm{~mm}$ (thermal sensory analyser, TSA-II, Medoc, Ramat Yishai, Israel) was applied perpendicularly to the sites to measure the thermal discomfort thresholds. The baseline temperature was set at $32{ }^{\circ} \mathrm{C}$. The temperature was then decreased or increased gradually at a rate of $3{ }^{\circ} \mathrm{C} / \mathrm{sec}$ until the participants started feeling discomfort. Three consecutive stimuli were delivered at each site (with a $20 \mathrm{sec}$ interval between the sites) and the mean value was recorded. The safety cut-off temperatures were set at $0{ }^{\circ} \mathrm{C}$ and $50{ }^{\circ} \mathrm{C}$. For the participants whose threshold was beyond the cut-off temperatures, these temperatures were recorded as their thresholds.

The algometer and thermode used in this study are the gold standard in the field of pain research to assess pressure and thermal measurement. The thermode is regularly calibrated and two of the authors (ZZ and DWLW) are experienced pain researchers and have used the same equipment and conducted a series of pain studies [35-37]. 


\subsection{Data Analysis}

Responses in the locations of arthritic pain and the intensities were calculated using the weighted average ranking method by the frequency of responses, with the highest-ranking being the location with the highest value of pain and the number of respondents. The average ranking was calculated as follows:

$$
\frac{i_{1}+i_{2}+i_{3}+i_{n}}{W}
$$

where $i$ is the pain intensity of arthritis chosen by the participant at a particular position and $w$ is the weight based on the number of subjects who chose the same position. If the number of the subject who chose the same location is one, the weight will be 12 , if two subjects, the weight will be 11 , and so forth.

Data were analyzed with SPSS software, version 22. The results are expressed as mean, standard deviation (SD) and $25^{\text {th }}$ and $75^{\text {th }}$ percentiles. Shapiro-Wilk test was performed to determine the normality of data distribution. Since significant non-normality was found, statistical significance was assessed with the Kruskal-Wallis $H$ test and Mann-Whitney $U$ test, the nonparametric alternative to the one-way analysis of variance and independent t-test. The Kruskal-Wallis $\mathrm{H}$ test was used to determine if there were statistically significant differences in pressure/cold/heat discomfort thresholds values between the tested locations for each participant and between the participants in each location. The Mann-Whitney $U$ test was used to determine if there were statistically significant differences between the cold pattern and heat pattern groups. Correlation analysis was employed to determine the strength of the relationships between the duration of arthritis and the discomfort thresholds for pressure, cold, and heat. All significance levels were set at $p<0.05$.

\section{Results}

\subsection{Demographic and Clinical Data of the Participants}

A total of 13 female participants (eight $O A$ and five RA) were included in the study. The mean age was $62.2 \pm 5.6$ years ( $48-70$ years), and the mean duration of arthritis was $8.3 \pm 10.7$ years ( $1-$ 40 years).

\subsection{Locations and Intensities of Arthritic Pain}

A total of 12 different locations were identified by the subjects as the locations where they had arthritic pain (Figure 5). Locations 5 and 3 showed the highest average ranking for pain, with nine and seven subjects for each location, respectively. 


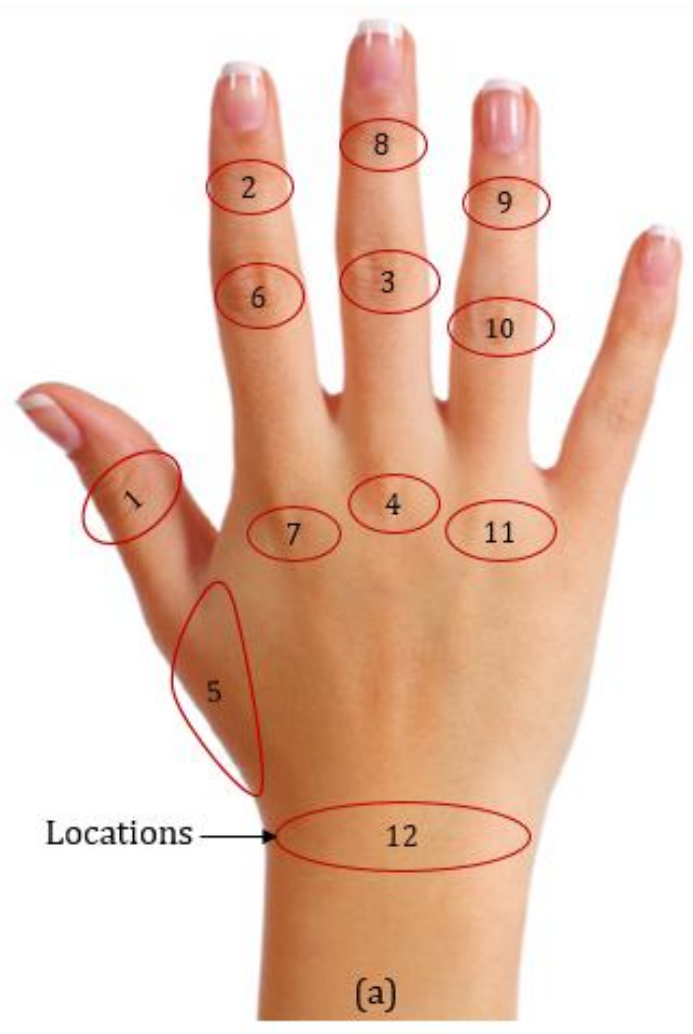

\begin{tabular}{ccc}
\hline $\begin{array}{c}\text { Average } \\
\text { ranking }\end{array}$ & $\begin{array}{c}\text { Number of } \\
\text { participants }\end{array}$ & Locations \\
\hline 12.50 & 9 & 5 \\
5.67 & 7 & 3 \\
3.88 & 5 & 1 \\
3.86 & 6 & 6 \\
1.70 & 3 & 2 \\
1.70 & 3 & 8 \\
1.30 & 3 & 10 \\
1.18 & 2 & 7 \\
0.91 & 2 & 12 \\
0.82 & 2 & 4 \\
0.54 & 1 & 11 \\
0.38 & 1 & 9 \\
\hline
\end{tabular}

(b)

Figure 3 (a) Locations of arthritic pain identified by the subjects and (b) weighted average ranking for each location.

\subsection{Pressure Discomfort Thresholds}

The mean pressure discomfort thresholds for all locations ranged from $53.0 \pm 22.6 \mathrm{kPa}$ to 383.8 $\pm 53.9 \mathrm{kPa}$. The Kruskal-Wallis $\mathrm{H}$ test demonstrated that pressure discomfort thresholds were significantly different between the participants at all tested locations $(p<0.05)$ (Table 1$)$. Furthermore, the analysis also revealed that seven of the participants had statistically significant different pressure discomfort thresholds at different locations of the hand (Table 1).

There was a moderate negative linear relationship between the duration of arthritis and pressure discomfort thresholds $(r=-0.65, \mathrm{P}<0.05)$ (Figure 4); the longer the duration of arthritis, the more sensitive the participants were toward the applied pressure. 
Table 1 Pressure discomfort thresholds (in $\mathrm{kPa}$ ) at different sites (mean $\pm \mathrm{SD}$ ).

\begin{tabular}{|c|c|c|c|c|c|c|c|}
\hline \multirow{2}{*}{ Participants } & \multicolumn{5}{|c|}{ Locations } & \multirow[b]{2}{*}{ Mean } & \multirow{2}{*}{$\begin{array}{c}\text { p-value } \\
\text { (within } \\
\text { participants) }\end{array}$} \\
\hline & P1 & P2 & P3 & P4 & P5 & & \\
\hline 1 & 159.9 & 176.5 & 185.4 & 161.8 & 226.5 & $182.0 \pm 27.0$ & 0.09 \\
\hline 2 & 375.6 & 428.6 & 298.1 & 408.9 & 318.7 & $366.0 \pm 56.3$ & 0.07 \\
\hline 3 & 196.1 & 235.4 & 225.6 & 225.6 & 323.6 & $241.3 \pm 48.3$ & $0.02 *$ \\
\hline 4 & 215.8 & 255.0 & 147.1 & 166.7 & 255.0 & $207.9 \pm 49.7$ & $0.03^{*}$ \\
\hline 5 & 402.1 & 461.0 & 362.9 & 379.5 & 313.8 & $383.9 \pm 54.0$ & 0.06 \\
\hline 6 & 166.7 & 294.2 & 199.1 & 235.4 & 333.4 & $245.8 \pm 68.1$ & $0.03^{*}$ \\
\hline 7 & 441.3 & 313.8 & 186.3 & 245.2 & 264.8 & $290.3 \pm 96.0$ & $0.03^{*}$ \\
\hline 8 & 372.7 & 333.4 & 264.8 & 372.7 & 176.5 & $304.0 \pm 83.8$ & 0.09 \\
\hline 9 & 235.4 & 176.5 & 117.7 & 156.1 & 255.0 & $188.1 \pm 56.6$ & $0.03^{*}$ \\
\hline 10 & 78.5 & 58.8 & 29.4 & 29.4 & 68.7 & $53.0 \pm 22.6$ & $0.02 *$ \\
\hline 11 & 98.1 & 98.1 & 58.8 & 68.7 & 58.8 & $76.5 \pm 20.1$ & 0.22 \\
\hline 12 & 173.6 & 45.1 & 55.9 & 52.0 & 57.9 & $76.9 \pm 54.3$ & 0.07 \\
\hline 13 & 156.9 & 107.9 & 88.3 & 117.7 & 117.7 & $117.7 \pm 25.0$ & $0.04 *$ \\
\hline Mean & $236.4 \pm 120.6$ & $229.6 \pm 134.4$ & $170.7 \pm 100.9$ & $201.5 \pm 125.5$ & $213.1 \pm 105.5$ & $210.3 \pm 26.0$ & \\
\hline $\begin{array}{l}\text { p-value (between } \\
\text { participants) }\end{array}$ & $0.00 *$ & $0.00 *$ & $0.00 *$ & $0.00 *$ & $0.00 *$ & & \\
\hline
\end{tabular}

$\mathrm{P} 1=$ first distal interphalangeal joint; $\mathrm{P} 2=\mathrm{P} 2-$ second distal interphalangeal joint; $\mathrm{P} 3=$ third proximal interphalangeal joint; $\mathrm{P} 4$ third metacarpophalangeal joint; $\mathrm{P} 5=$ first carpometacarpal joint; * ${ }^{*}=$ ignificant $\mathrm{p}$ values. 


\subsection{Thermal Discomfort Thresholds}

\subsubsection{Cold Discomfort Threshold}

The sensitivity toward cold was found to be different between the participants for all locations $(p<0.05)$ (Table 2). Moreover, the analysis also revealed that more than half of the participants had statistically significantly different cold discomfort thresholds at different locations of the hand.

There was a moderate linear relationship between the cold discomfort thresholds and duration of arthritis $(r=0.61, p<0.05)$ (Figure 4), which demonstrated that the longer the years in OA or RA, the higher the cold discomfort threshold was or, in other words, the person is more sensitive to cold.
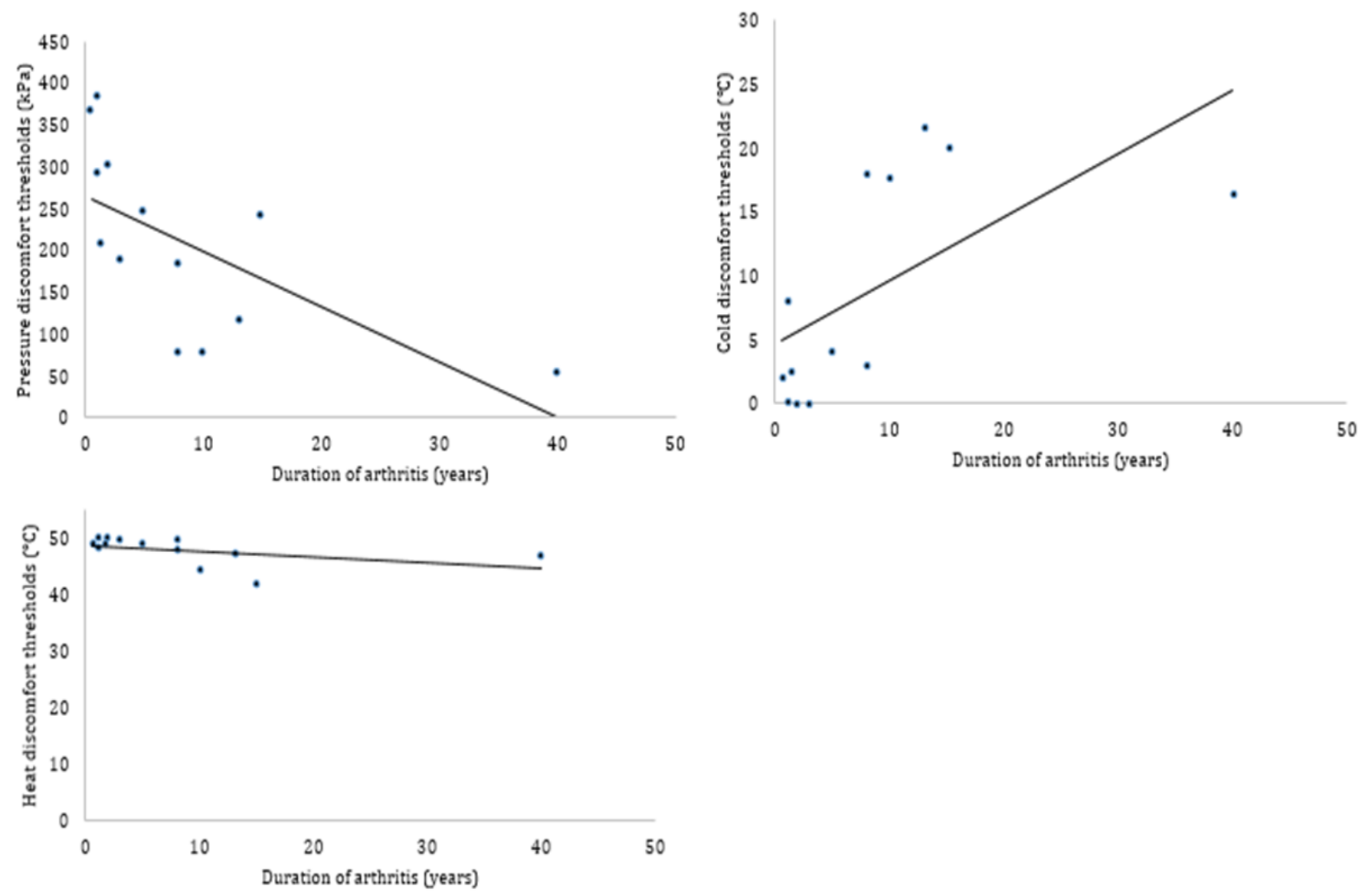

Figure 4 Relationship of pressure, cold, and heat discomfort thresholds with the duration of arthritis. 
Table 2 Cold discomfort thresholds at the different sites of the hand (mean $\pm S D$ ).

\begin{tabular}{|c|c|c|c|c|c|c|c|}
\hline \multirow[t]{2}{*}{ Participants } & \multicolumn{5}{|c|}{ Locations } & \multirow{2}{*}{ Mean } & \multirow{2}{*}{$\begin{array}{c}\text { p-value (among the } \\
\text { participants) }\end{array}$} \\
\hline & P1 & $\mathbf{P 2}$ & P3 & P4 & P5 & & \\
\hline 1 & 3.8 & 4.5 & 2.4 & 3.1 & 1.5 & $3.1 \pm 1.2$ & $0.05^{*}$ \\
\hline 2 & 0.0 & 0.0 & 4.0 & 3.1 & 3.2 & $2.1 \pm 1.9$ & $0.03 *$ \\
\hline 3 & 28.8 & 24.3 & 5.2 & 27.8 & 15.1 & $20.2 \pm 10.0$ & $0.04 *$ \\
\hline 4 & 0.5 & 0.2 & 7.2 & 0.9 & 5.0 & $2.8 \pm 3.2$ & $0.02 *$ \\
\hline 5 & 0.0 & 0.0 & 1.3 & 0.0 & 0.0 & $0.3 \pm 0.6$ & 0.41 \\
\hline 6 & 5.1 & 6.3 & 9.5 & 0.0 & 0.0 & $4.2 \pm 4.1$ & $0.02 *$ \\
\hline 7 & 0.0 & 0.0 & 19.1 & 5.8 & 15.3 & $8.0 \pm 8.8$ & $0.01 *$ \\
\hline 8 & 0.0 & 0.0 & 0.0 & 0.0 & 0.0 & $0.0 \pm 0.0$ & 1.00 \\
\hline 9 & 0.0 & 0.0 & 0.0 & 0.0 & 0.0 & $0.0 \pm 0.0$ & 1.00 \\
\hline 10 & 19.4 & 17.9 & 23.1 & 20.0 & 0.0 & $16.1 \pm 9.2$ & $0.02 *$ \\
\hline 11 & 19.5 & 16.7 & 18.2 & 16.9 & 17.8 & $17.8 \pm 1.1$ & 0.16 \\
\hline 12 & 22.9 & 9.9 & 22.3 & 17.8 & 17.2 & $18.0 \pm 5.2$ & $0.03^{*}$ \\
\hline 13 & 25.1 & 23.8 & 22.7 & 24.4 & 13.0 & $21.8 \pm 5.0$ & $0.05^{*}$ \\
\hline Mean & $9.6 \pm 11.5$ & $8.0 \pm 9.5$ & $10.4 \pm 9.3$ & $9.2 \pm 10.5$ & $6.8 \pm 7.6$ & $8.8 \pm 1.4$ & \\
\hline $\begin{array}{l}\text { p-value (between } \\
\text { participants) }\end{array}$ & $0.00 *$ & $0.00 *$ & $0.00 *$ & $0.00 *$ & $0.00^{*}$ & & \\
\hline
\end{tabular}

$\mathrm{P} 1=$ first distal interphalangeal joint; $\mathrm{P} 2=\mathrm{P} 2-$ second distal interphalangeal joint; $\mathrm{P} 3=$ third proximal interphalangeal joint; $\mathrm{P} 4$ third metacarpophalangeal joint; P5= first carpometacarpal joint; ${ }^{*}=$ significant $p$ values. 


\subsubsection{Heat Discomfort Threshold}

The sensitivity toward heat was found to be different between the participants at different locations $(p<0.05)$ (Table 3$)$. Only two of the participants showed significantly different heat discomfort thresholds at different locations of the hand. One participant was very sensitive toward the heat stimuli with the mean heat discomfort thresholds of $40.9{ }^{\circ} \mathrm{C}$. There was a weak negative linear relationship between the heat discomfort thresholds and duration of arthritis $(r=-0.47)$ (Figure 4). In addition, no statistically significant difference was found between the heat discomfort thresholds and the duration of arthritis.

Figure 5 shows the range of 5 th to 95 th percentiles for both cold and heat discomfort thresholds. The range was larger for the cold discomfort thresholds compared to the heat discomfort thresholds.

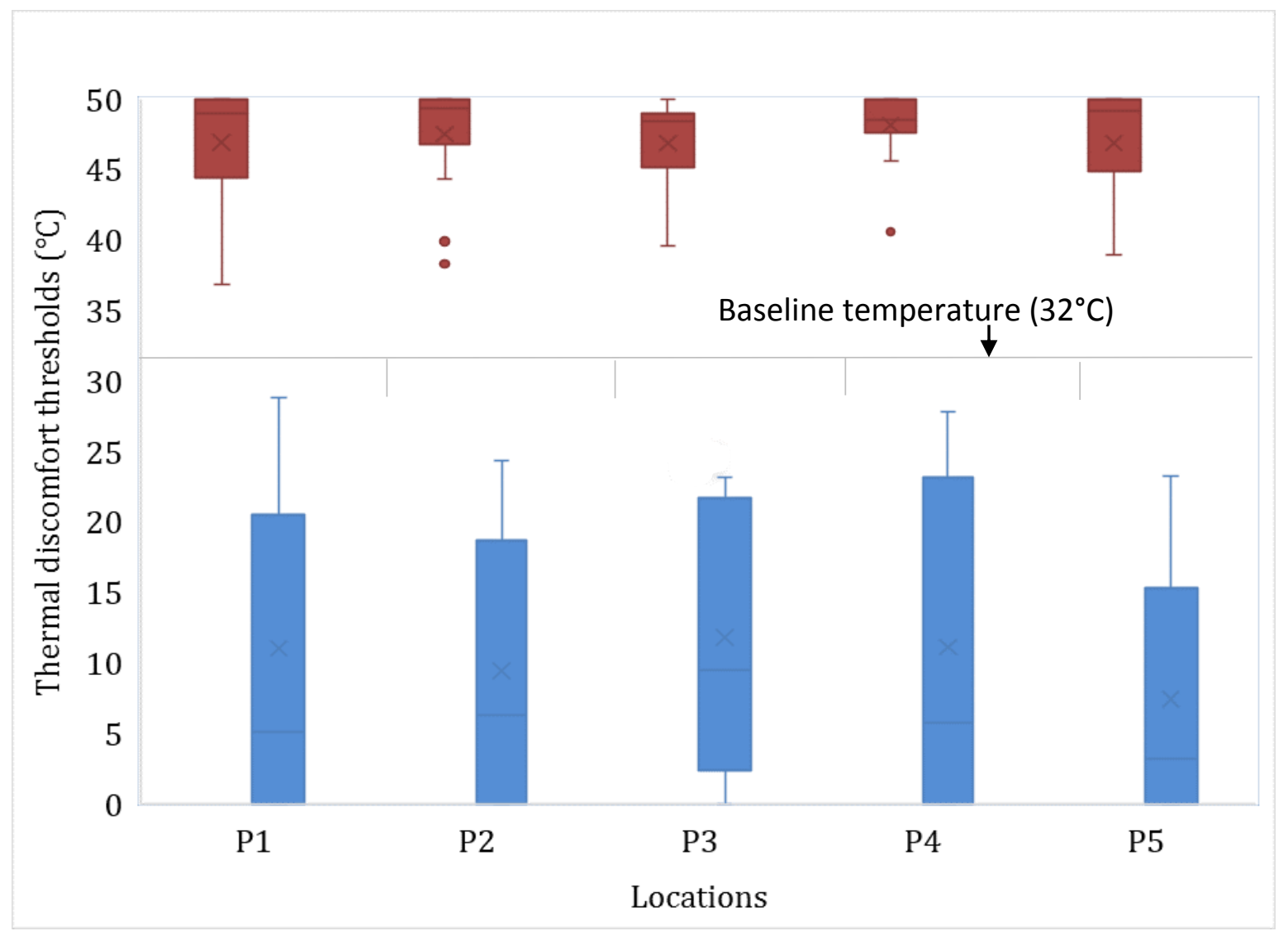

Figure 5 Cold (blue) and heat (red) discomfort thresholds at the different sites of the hand. 
Table 3 Heat discomfort thresholds at different sites of hand (mean \pm SD)

\begin{tabular}{|c|c|c|c|c|c|c|c|}
\hline Participants & \multicolumn{5}{|c|}{ Locations } & Mean & $\begin{array}{c}\text { p-value (within } \\
\text { participants) }\end{array}$ \\
\hline 1 & 49.1 & 50.0 & 50.3 & 47.7 & 51.3 & $49.7 \pm 1.4$ & 0.18 \\
\hline 2 & 50.0 & 50.0 & 48.6 & 48.6 & 47.0 & $48.8 \pm 1.2$ & 0.07 \\
\hline 3 & 36.9 & 38.3 & 48.8 & 47.4 & 39.0 & $42.1 \pm 5.6$ & $0.02 *$ \\
\hline 6 & 48.5 & 49.4 & 46.6 & 50.0 & 49.2 & $48.7 \pm 1.3$ & 0.57 \\
\hline 7 & 50.0 & 50.0 & 48.0 & 48.5 & 44.3 & $48.2 \pm 2.3$ & 0.17 \\
\hline 8 & 50.0 & 50.0 & 50.0 & 50.0 & 50.0 & $50.0 \pm 0.0$ & 0.52 \\
\hline 9 & 50.0 & 49.2 & 49.2 & 50.0 & 50.0 & $49.7 \pm 0.4$ & 1.00 \\
\hline 12 & 48.8 & 46.1 & 48.5 & 50.0 & 45.5 & $47.8 \pm 1.9$ & 0.67 \\
\hline 13 & 49.0 & 49.8 & 48.3 & 45.6 & 42.9 & $47.1 \pm 2.8$ & 0.13 \\
\hline Mean & $47.6 \pm 3.9$ & $47.7 \pm 4.0$ & $47.7 \pm 3.0$ & $48.2 \pm 2.7$ & $46.9 \pm 4.3$ & $47.6 \pm 0.5$ & \\
\hline $\begin{array}{l}\text { p-value (between } \\
\text { participants) }\end{array}$ & $0.00 *$ & $0.01 *$ & $0.02 *$ & $0.01 *$ & $0.00 *$ & & \\
\hline
\end{tabular}

$\mathrm{P} 1=$ first distal interphalangeal joint; $\mathrm{P} 2=$ second distal interphalangeal joint; $\mathrm{P} 3=$ third proximal interphalangeal joint; $\mathrm{P} 4$ third metacarpophalangeal joint; P5= first carpometacarpal joint; ${ }^{*}=$ significant $p$ values. 


\subsubsection{Classification of Participants into Cold Pattern and Heat Pattern Groups}

According to Cold-Heat pattern questionnaire, eight participants were classified into the cold pattern group, i.e., sensitive to cold and five were placed into the heat pattern group, i.e., sensitive to heat (Table A, Supplementary material). As shown in Table 4, the participants who are in heat pattern group recorded slightly higher mean pressure discomfort thresholds than participants in cold pattern group; however, there was no statistically significant difference in the mean pressure discomfort thresholds between the two groups (Table 4).

The participants who were in cold pattern group recorded higher mean of cold discomfort thresholds $\left(10.3^{\circ} \mathrm{C}\right)$ in comparison to the participants in the heat pattern group; which mean that they were more sensitive toward cold stimuli. However, no statistically significant difference was found between the two groups. For the heat discomfort threshold, both groups recorded a mean value of $47.6^{\circ} \mathrm{C}$.

Table 4 Pressure, cold, and heat discomfort thresholds of participants in the different groups (mean $\pm \mathrm{SD}$ ).

\begin{tabular}{llll}
\hline Groups & $\begin{array}{l}\text { Pressure discomfort } \\
\text { thresholds }(\mathrm{kPa})\end{array}$ & $\begin{array}{l}\text { Cold discomfort } \\
\text { thresholds }\left({ }^{\circ} \mathrm{C}\right)\end{array}$ & $\begin{array}{l}\text { Heat discomfort } \\
\text { thresholds }\left({ }^{\circ} \mathrm{C}\right)\end{array}$ \\
\hline Cold pattern & $199.1 \pm 110.7$ & $10.3 \pm 9.6$ & $47.6 \pm 2.5$ \\
Heat pattern & $228.1 \pm 115.82$ & $6.4 \pm 7.0$ & $47.6 \pm 3.8$ \\
\hline p-value & $>0.05$ & $>0.05$ & $>0.05$ \\
\hline
\end{tabular}

\section{Discussion}

Therapeutic gloves are prescribed for wearing during the day and/or at night to relieve arthritic symptoms and improve hand function in arthritis patients. Therefore, it is important for the gloves to be comfortable to wear. Identifying the sensitivity of individuals toward the pressure and thermal stimuli is crucial to design a glove that is comfortable and functional. To the best of our knowledge, no published studies investigated the pressure and thermal discomfort thresholds as a method used in the design of therapeutic gloves. This is the first pilot study in this regard.

The locations identified by the subjects as the locations where they feel arthritic pain agrees with those in previous studies $[30,38]$. OA commonly involves the DIP, PIP, and first CMC joints of the hand while RA commonly involves the PIP and MCP joints of the hand. Location P3 recorded the highest sensitivity toward pressure and cold. These points correspond to the results of the location of arthritic pain identified by the subjects in Figure 3. Location 3 was the second-highest location identified by the subjects. Identifying the locations of arthritic pain, besides the location of inflamed joints, can help the therapeutic glove designers and manufacturers develop a product with targeted treatment locations. 
A moderate linear relationship was found between the duration of arthritis and pressure and cold discomfort thresholds. Those with a longer duration of arthritis were more sensitive toward pressure and cold. The relationship between discomfort thresholds and duration of pain is in line with those reported earlier [13-15]. The duration of hand arthritis might have resulted in the different degrees of central sensitization. However, the within-subject variations in the discomfort thresholds to pressure, cold, and heat at different sites of the hand may also reflect the existence of peripheral sensitization in this cohort. Our observations on the fluctuation in discomfort thresholds are consistent with previous studies [13-16, 39]. Our findings highlight the importance of considering not only the duration of arthritis for individual patients but also their site-related pain sensitivity when designing and prescribing gloves.

Some participants were found to be hypersensitive to pressure stimulation with discomfort thresholds lower than $100 \mathrm{kPa}$. Therefore, gloves with lower compression level should be available for people who are sensitive to pressure stimulation. The pressure sensitivity was not uniformly distributed over the hand for more than half of the participants; similar to that reported in previous studies $[12,15,21,22,40,41]$. The mean pressure discomfort threshold was noticeably lower at P3 (third PIP joint) and highest at PI (first DIP joint) locations. Since the pressure sensitivity is not uniformly distributed over the hand, regional variation in the responses of the pressure stimuli should be taken into consideration in the design of therapeutic gloves.

This study found that some subjects have a different level of sensitivity toward cold and heat in different areas of the hand. Since there was a significant difference in cold and heat stimuli at different areas of hand, it was important to evaluate the distributions of sensitivity at the hand and translate it into hand mapping for the glove design. Further, considerable variations between the participants were also found for the cold discomfort thresholds in contrast to very low variations for heat discomfort thresholds. The cold sensation is known to be more subjective to variation in human and thus difficult to evaluate [19, 20,42].

Significant differences were observed between the participants in their pressure, cold or heat discomfort thresholds. This disparity among the participants in their pressure and thermal discomfort threshold emphasized that different types and designs of therapeutic gloves are crucial to maintain the wear comfort of the user and enhance the therapy effectiveness. Therapeutic gloves that are designed to provide warmth (heat therapy) to the hand are more suitable for people who are sensitive to cold. This type of gloves is not recommended to an individual who has low heat discomfort threshold because it will cause discomfort to the wearer. A therapeutic glove designed to provide pressure therapy might be more suitable for this group of people [43].

The present study found no statistically significant difference in the mean pressure, cold and heat discomfort thresholds between the cold pattern and heat pattern groups. The small sample size could be the reason for the lack of statistical significance in the present study.

The data from this study can be used to map the pressure and thermal discomfort thresholds of the hand which could be helpful in designing an optimum level of therapy without compromising the comfort of the user. These factors together with the patient preference of design and materials of the glove should be considered in order to encourage patient compliance and optimal therapy effectiveness. 


\section{Limitations and Future Studies}

Although the results of the current study are relevant for a better understanding of the pressure and thermal stimulation in the design of gloves, some limitations should be considered. Our sample cannot be taken as the representative of the general population since only female participants above the age of 40 years were recruited. A population-based study with a greater sample size is needed to derive more generalized interpretations of the results. Participants with warm and inflamed joints might be more sensitive toward thermal thresholds, future studies could investigate the relationship between inflamed joints and thermal sensitivity. Since all participants underwent pressure stimulation first, followed by cold and then heat stimulation in a fixed order, there might be a potential order effect on the results. We recommend that future studies should randomize both the order of stimulus and the locations of testing to eliminate the potential order effect.

This exploratory pilot study focused only on identifying the spatial distribution of participants' sensitivity to pressure, heat, and cold stimulation in their hands rather than on sensory sensitivity per se. Consequently, the normality of the participants' sensory perception was not examined. It is therefore unknown if some participants had a sensory deficit. The lack of such information should not impact the current findings but might impact the clinical relevance of the data. Patients with sensory deficit may require special consideration in the design of their gloves. Future studies should investigate participants' sensory perception. The classifications of patients into different groups based on Cold-Heat pattern questionnaire and their sensitivity toward cold and heat stimuli have potential for personalized treatment (targeting the right therapeutic product to the right patient). However, since this is a pilot study, future studies with larger sample sizes with a wider age group involving male participants are needed to substantiate these findings. Lastly, future studies must exclude participants with comorbid fibromyalgia syndrome and Raynaud's Syndrome as these diseases could influence the pain and thermal thresholds.

\section{Conclusion}

Patients with hand OA or RA present significant variations in terms of pressure, cold, and heat discomfort thresholds. Those with a longer disease duration are more sensitive to pressure and cold stimulation. An ergonomic approach based on the variations in the distribution of individual sensitivity to pressure and thermal stimulation is recommended while designing therapeutic gloves. The current practice in glove prescription does not take these important aspects into account, so determining the initial magnitude and drawing attention to their importance was the initial aim. The role of the Cold-Heat pattern questionnaire in assisting the design of therapeutic gloves for particular groups of people requires further research. Studies with larger sample sizes are needed to confirm our results and to make more specific recommendations for the design of therapeutic gloves.

\section{Author Contributions}

Dr. Nasir is the primary author. She conceptualized the study, collected and analyzed the data, and prepared the original manuscript draft. Prof. Troynikov and Assoc. Prof. Zheng provided overall 
feedback on the study design. Dr. Wong Lit Wan contributed to the protocol of the pain assessments. All authors reviewed and edited the entire manuscript.

\section{Funding}

This research received no specific grants from any funding agency in the public, commercial, or not-for-profit sectors.

\section{Competing Interests}

The authors have declared that no competing interests exist.

\section{Additional Materials}

Table A The cold pattern and heat pattern score and grouping for each participant.

\begin{tabular}{|l|l|l|l|l|}
\hline Participants & Cold pattern score & Heat pattern score & Cold-Heat Pattern Score & Groups \\
\hline 1 & $2 / 10$ & $5 / 10$ & 3 & heat \\
\hline 2 & $5 / 10$ & $3 / 10$ & -2 & cold \\
\hline 3 & $6 / 10$ & $4 / 10$ & -2 & cold \\
\hline 4 & $6 / 10$ & $7 / 10$ & 1 & heat \\
\hline 5 & $6 / 10$ & $8 / 10$ & 2 & heat \\
\hline 6 & $6 / 10$ & $5 / 10$ & -1 & cold \\
\hline 7 & $1 / 10$ & $6 / 10$ & 5 & heat \\
\hline 8 & $6 / 10$ & $0 / 10$ & -6 & cold \\
\hline 9 & $3 / 10$ & $1 / 10$ & -2 & cold \\
\hline 10 & $6 / 10$ & $1 / 10$ & -5 & cold \\
\hline 11 & $0 / 10$ & $1 / 10$ & 1 & heat \\
\hline 12 & $6 / 10$ & $1 / 10$ & -5 & cold \\
\hline 13 & $8 / 10$ & $4 / 10$ & -4 & cold \\
\hline
\end{tabular}

Below are the conditions regarding the "Cold-Heat" pattern. Please answer either "Yes" or "No" based on the health status during the preceding week.

Table B Cold-heat pattern questionnaire adapted from Ryu, et al. [23].

\begin{tabular}{|l|l|l|}
\hline Symptoms & Conditions & Answer \\
\hline Cold pattern & I've had aversion to cold. & \\
\cline { 1 - 2 } Aversion to cold & I've preferred warmth. & \\
\hline Preference for heat & \\
\hline
\end{tabular}


OBM Integrative and Complementary Medicine 2019; 4(3), doi:10.21926/obm.icm.1903053

\begin{tabular}{|c|c|}
\hline Abdominal coldness & I've experienced coldness in the abdomen. \\
\hline Coldness of the limbs & I've felt coldness in the hand or foot. \\
\hline Cold pain & $\begin{array}{l}\text { I've had painful sensations of cold that were } \\
\text { relieved by warmth. }\end{array}$ \\
\hline Pale face & My face has been pale. \\
\hline Absence of thirst & I've not been thirsty. \\
\hline Long voiding of colorless urine & I've produced large volumes of colorless urine. \\
\hline Loose stools & I've delivered loose stools. \\
\hline $\begin{array}{l}\text { Thin clear sputum and nasal } \\
\text { mucus }\end{array}$ & $\begin{array}{l}\text { I've produced thin and clear sputum or nasal } \\
\text { mucus. }\end{array}$ \\
\hline \multicolumn{2}{|l|}{ Heat pattern } \\
\hline Preference for cold & I've preferred sensations of cold. \\
\hline Body heat & I've felt excessively warm. \\
\hline Heat of the limbs & My palms or soles have felt hot. \\
\hline Feverish pain & I've experienced feverish pain. \\
\hline Flushed face and eye & My face or eyes have been flushed. \\
\hline Thirst & I've been thirsty or my mouth has felt dry. \\
\hline $\begin{array}{l}\text { Scanty voiding of dark-colored } \\
\text { urine }\end{array}$ & $\begin{array}{l}\text { I've produced minimal volumes of urine that were } \\
\text { dark-colored. }\end{array}$ \\
\hline Dry stool & My stools have been dry. \\
\hline $\begin{array}{l}\text { Thick yellow sputum and nasal } \\
\text { mucus }\end{array}$ & $\begin{array}{l}\text { I've produced thick yellow sputum or nasal } \\
\text { mucus. }\end{array}$ \\
\hline Hot breath & My breath has been hot. \\
\hline
\end{tabular}

\section{References}

1. Klocke ML. Aquatic exercise and perceived functional outcomes in individuals with arthritis [M.S]: D'Youville College; 2000.

2. Syngle A. Arthritis and its treatment. In: Rattan SIS, Kassem M, editors. Prevention and treatment of age-related diseases. Netherlands: Springer; 2006. p. 105-132.

3. Moriyama H, Bagchi D. Arthritis, aging society, exercise, nutrition and other precautionary measures. In: Raychaudhuri SP, editor. Arthritis. Florida, USA: CRC Press; 2011. p. 559-561.

4. Nasir SH, Troynikov O, Massy-Westropp N. Therapy gloves for patients with rheumatoid arthritis: A review. Ther Adv Musculoskel Dis. 2014; 6: 226-237. 
5. Hammond A, Jones V, Prior $Y$. The effects of compression gloves on hand symptoms and hand function in rheumatoid arthritis and hand osteoarthritis: A systematic review. Clin Rehab. 2016; 30: 213-224.

6. Swezey RL, Spiegel TM, Cretin S, Clements P. Arthritic hand response to pressure gradient gloves. Arch Phys Medicine Rehab. 1979; 60: 375-377.

7. Culic DD, Battaglia MC, Wichman CBS, Schmid FR. Efficacy of compression gloves in rheumatoid arthritis. Am J Phys Med Rehab. 1979; 58: 278-284.

8. Macintyre L, Baird M. Pressure garments for use in the treatment of hypertrophic scars-a review of the problems associated with their use. Burns. 2006; 32: 10-15.

9. Das A, Alagirusamy R. Garment fit and comfort. Science in clothing comfort: Woodhead Publishing: India; 2010.

10. Dianat I, Haslegrave CM, Stedmon AW. Design options for improving protective gloves for industrial assembly work. Appl Ergon. 2014; 45: 1208-1217.

11. Johansson L, Kjellberg A, Kilbom A, Hagg GA. Perception of surface pressure applied to the hand. Ergonomics. 1999; 42: 1274-1282.

12. Chiarotto A, Fernandez-de-Las-Penas C, Castaldo M, Negrini S, Villafane JH. Widespread pressure pain hypersensitivity in elderly subjects with unilateral thumb carpometacarpal osteoarthritis. Hand (NY). 2013; 8: 422-429.

13. Arendt-Nielsen L, Egsgaard LL, Petersen KK, Eskehave TN, Graven-Nielsen T, Hoeck HC, et al. A mechanism-based pain sensitivity index to characterize knee osteoarthritis patients with different disease stages and pain levels. Eur J Pain. 2015; 19: 1406-1417.

14. Sofat N, Smee C, Hermansson M, Howard M, Baker EH, Howe FA, et al. Functional MRI demonstrates pain perception in hand osteoarthritis has features of central pain processing. J Biomed Graph Comput. 2013; 3.

15. Fernandez-de-Las-Penas C, Madeleine P, Martinez-Perez A, Arendt-Nielsen L, Jimenez-Garcia R, Pareja JA. Pressure pain sensitivity topographical maps reveal bilateral hyperalgesia of the hands in patients with unilateral carpal tunnel syndrome. Arthrit Care Res. 2010; 62: 1055-1064.

16. Chiarotto A, Fernandez-de-las-Peñas C, Castaldo M, Villafañe JH. Bilateral pressure pain hypersensitivity over the hand as potential sign of sensitization mechanisms in individuals with thumb carpometacarpal osteoarthritis. Pain Med. 2013; 14: 1585-1592.

17. McKnight PT, Kwoh CK. Randomized, controlled trial of compression gloves in rheumatoid arthritis. Arthrit Care Res. 1992; 5: 223-227.

18. Li X, Petrini L, Defrin R, Madeleine P, Arendt-Nielsen L. High resolution topographical mapping of warm and cold sensitivities. Clin Neurophysiol. 2008; 119: 2641-2646.

19. Wakolbinger R, Roche AD, Stockinger T, Gustorff B, Aszmann OC. Multiregion thermal sensitivity mapping of the hand. J Plast Reconstr Aes Surg. 2014; 67: 1541-1547.

20. Hagander LG, Midani HA, Kuskowski MA, Parry GJG. Quantitative sensory testing: effect of site and skin temperature on thermal thresholds. Clin Neurophysiol. 2000; 111: 17-22.

21. Muralidhar A, Bishu RR. Safety performance of gloves using the pressure tolerance of the hand. Ergonomics. 2000; 43: 561-572. 
22. Muralidhar A, Bishu RR, Hallbeck MS. The development and evaluation of an ergonomic glove. Appl Ergon. 1999; 30: 555-563.

23. Ryu $H$, Lee $H$, Kim $H$, Kim J. Reliability and validity of a cold-heat pattern questionnaire for traditional Chinese medicine. J Altern Complement Med. 2010; 16: 663-667.

24. van Wietmarschen HA, Dai W, van der Kooij AJ, Reijmers $T H$, Schroën $Y$, Wang $M$, et al. Characterization of rheumatoid arthritis subtypes using symptom profiles, clinical chemistry and metabolomics measurements. PLoS ONE. 2012; 7: e44331.

25. Lu C, Zha Q, Chang A, He Y, Lu A. Pattern differentiation in traditional chinese medicine can help define specific indications for biomedical therapy in the treatment of rheumatoid arthritis. J Altern Complement Med. 2009; 15: 1021-1025.

26. Nasir SH, Troynikov O. Influence of hand movement on skin deformation: A therapeutic glove design perspective. Appl Ergon. 2017; 60: 154-162.

27. Rydholm M, Book C, Wikstrom I, Jacobsson L, Turesson C. Course of grip force impairment in patients with early rheumatoid arthritis over the first five years after diagnosis. Arthrit Care Res. 2018; 70: 491-498.

28. Hunter DJ, Schofield D, Callander E. The individual and socioeconomic impact of osteoarthritis. Nat Rev Rheumatol. 2014; 10: 437-441.

29. Koo TK, Guo J-y, Brown CM. Test-retest reliability, repeatability, and sensitivity of an automated deformation-controlled indentation on pressure pain threshold measurement. J Manip Physiol Ther. 2013; 36: 84-90.

30. Manno R. Osteoarthritis: Epidemiology \& risk factors. Johns Hopkins Arthritis Center; 2012. Available from: http://www.hopkinsarthritis.org/arthritis-info/osteoarthritis/oa-clinicalpresentation/.

31. Ruffing V, Bingham C. Rheumatoid arthritis signs and symptoms. Johns Hopkins Arthritis Center; 2016. Available from: http://www.hopkinsarthritis.org/arthritis-info/rheumatoid-arthritis/rasymptoms/.

32. Combe B. Early rheumatoid arthritis: Strategies for prevention and management. Best Pract Res Clin Rheumatol. 2007; 21: 27-42.

33. Bellamy N, Campbell J, Haraoui B, Buchbinder R, Hobby K, Roth JH, et al. Dimensionality and clinical importance of pain and disability in hand osteoarthritis: Development of the Australian/Canadian (AUSCAN) Osteoarthritis Hand Index. Osteoarthr Cartilage. 2002; 10: 855862.

34. Dahaghin S, Bierma-Zeinstra SMA, Ginai AZ, Pols HAP, Hazes JMW, Koes BW. Prevalence and pattern of radiographic hand osteoarthritis and association with pain and disability (the Rotterdam study). Ann Rheum Dis. 2005; 64: 682-687.

35. Wan DWL, Arendt-Nielsen L, Wang K, Xue CC, Wang Y, Zheng Z. Pain adaptability in individuals with chronic musculoskeletal pain is not associated with conditioned pain modulation. J Pain. 2018; 19: 897-909.

36. Zheng Z, Wang K, Yao D, Xue CC, Arendt-Nielsen L. Adaptability to pain is associated with potency of local pain inhibition, but not conditioned pain modulation: A healthy human study. Pain. 2014; 155: 968-976. 
37. Zheng Z, Wong Lit Wan D, Arendt-Nielsen L, Yao DY, Iversen G, Xue CC, et al. Being adaptive to pain enhances sham acupuncture analgesia: A crossover healthy human study. J Acupunct Merid Stud. 2017; 10: 385-395.

38. Arden N, Nevitt MC. Osteoarthritis: Epidemiology. Best Pract Res Clin Rheumatol. 2006; 20: 3-25.

39. Dhondt W, Willaeys T, Verbruggen LA, Oostendorp RA, Duquet W. Pain threshold in patients with rheumatoid arthritis and effect of manual oscillations. Scand J Rheumatol. 1999; 28: 88-93.

40. Imamura M, Chen J, Matsubayashi SR, Targino RA, Alfieri FM, Bueno DK, et al. Changes in pressure pain threshold in patients with chronic nonspecific low back pain. Spine. 2013; 38: 20982107.

41. Fransson-Hall C, Kilbom Å. Sensitivity of the hand to surface pressure. Appl Ergon. 1993; 24: 181189.

42. Navarro X, Kennedy WR. Evaluation of thermal and pain sensitivity in type I diabetic patients. J Neurol Neurosur Ps. 1991; 54: 60-64.

43. Krimmel G. The construction and classification of compression garments. Aberdeen; 2009.

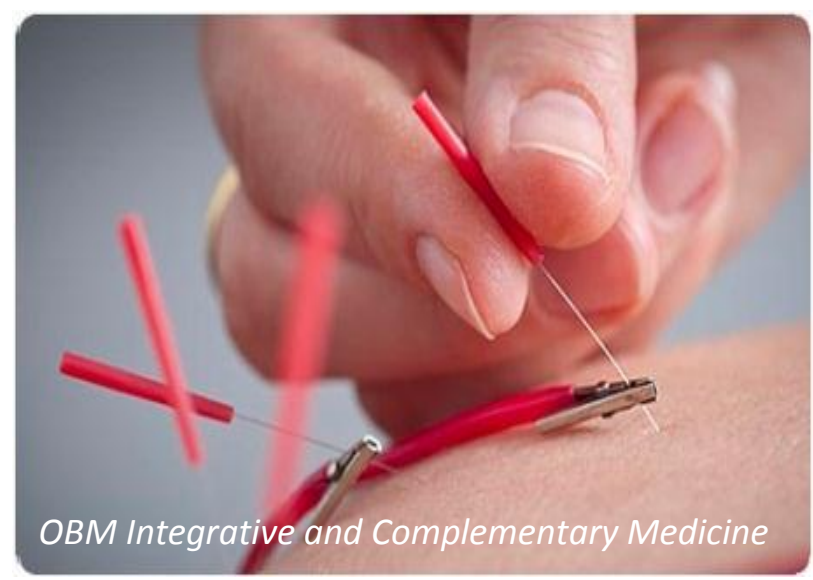

Enjoy $O B M$ Integrative and Complementary Medicine by:

1. Submitting a manuscript

2. Joining in volunteer reviewer bank

3. Joining Editorial Board

4. Guest editing a special issue

For more details, please visit: http://www.lidsen.com/journals/icm 